\title{
FLUXOS TURBULENTOS DE DIÓXIDO DE CARBONO SOBRE O RESERVATÓRIO DA USINA HIDRELÉTRICA DE ITAIPU - PR
}

\author{
Fernando Augusto Silveira Armani ${ }^{1}$, Nelson Luís da Costa Dias ${ }^{1,2}$, Bianca Luhm Crivellaro ${ }^{1}$, \\ Tomás Luís Guimarães Chor ${ }^{1}$ \\ ${ }^{1}$ Programa de Pós-Graduação em Engenharia Ambiental, UFPR - Brasil; \\ ${ }^{2}$ Departamento de Engenharia Ambiental, UFPR - Brasil
}

\section{RESUMO}

Fluxos turbulentos de dióxido de carbono $\left(\mathrm{CO}_{2}\right)$ foram medidos sobre o reservatório da usina hidrelétrica de Itaipu durante 13 dias de dezembro de 2012. Nessa campanha, notou-se que no período diurno os fluxos de $\mathrm{CO}_{2}$ eram controlados pela radiação solar incidente, sendo que se constatou fixação de $\mathrm{CO}_{2}$ pelo reservatório durante o dia.

\section{ABSTRACT}

$\mathrm{CO} 2$ turbulent fluxes were measured on the Itaipu's reservoir during 13 days of december 2012. In these days we verified that these fluxes were controlled by solar radiation because when the radiation was bigger, the fluxes was more negative.

\section{INTRODUÇÃO}

O dióxido de carbono é um dos principais gases estufa da atmosfera. Devido às atividades antropogênicas, a concentração desse gás na atmosfera tem aumentado significativamente. Assim, para entender o ciclo desse gás na natureza, diversos estudos têm sido realizados para caracterizar as suas diferentes fontes e sumidouros. Neste trabalho, nosso foco é quantificar a transferência do dióxido de carbono entre o reservatório da usina hidrelétrica de Itaipu e a atmosfera e tentar identificar as variáveis que controlam o fluxo desse gás no reservatório em uma campanha de monitoramento que foi realizada no mês de dezembro de 2012.

O primeiro estudo publicado sobre a emissão de gases estufa de reservatórios de usinas hidrelétricas foi o de Rudd et al. (1993). Rudd et al. (1993) obtiveram resultados em suas medições que os levaram a concluir que a emissão de gases de efeito estufa por unidade de energia produzida de usinas hidrelétricas pode ser significativa em relação a de usinas termelétricas de combustíveis fósseis. O trabalho de Rudd et al. (1993) gerou vários debates e novas pesquisas. Assim, atualmente se sabe que a emissão do $\mathrm{CO}_{2}$ por usinas hidrelétricas está relacionada com vários fatores, entre os quais se incluem: idade e latitude do reservatório, cobertura vegetal da área alagada, tecnologia empregada para geração de energia elétrica, temperatura da água, temperatura do ar, e área de drenagem, entre outros (Barros, 2011).

Há diversas técnicas para medir o fluxo de dióxido de carbono na natureza. Uma tecnologia que tem sido bastante utilizada é o Método de Medição de Covariâncias Turbulentas (MCT). O MCT é baseado em medidas micrometeorológicas, em que são usados analisadores de alta frequência para medir as flutuações das concentrações turbulentas. Uma das principais vantagens deste método é que o MCT não altera a interface ar/água e as medições são realizadas continuamente. No entanto, para este método há algumas suposições que devem ser atendidas em um determinado período médio de tempo; por exemplo, considera-se que o escoamento está completamente desenvolvido e em estado estacionário, que na horizontal o escoamento é homogêneo, e que a velocidade média vertical do vento é próxima de zero. Além disso, quando o ponto de medição é fixo, como no nosso caso, as 
medições não têm grande cobertura espacial, sendo representativas apenas da pista de vento que alcança os sensores, área denominada footprint.

Neste trabalho, aplicamos MCT para o cálculo dos fluxos de $\mathrm{CO}_{2}$ para médias em bloco de uma hora. Para minimizar o efeito da inclinação da superfície e do possível desnivelamento do anemômetro sônico, aplicamos uma rotação de coordenadas nas componentes da velocidade do vento para anular a velocidade horizontal transversal e a velocidade vertical. Além disso, estimamos uma velocidade vertical com a correção WPL (Paw U et al., 2000). O fluxo de $\mathrm{CO}_{2}$ com a correção WPL é dado por:

$$
F_{c}=\bar{w} \overline{\rho_{c}}+\overline{w^{\prime} \rho^{\prime}}
$$

em que $\rho_{c}$ é a densidade do $\mathrm{CO}_{2}, w$ a velocidade vertical, barras verticais indicam médias $\mathrm{e} \rho_{c}^{\prime} \mathrm{e}$ $w^{\prime}$ são suas respectivas flutuações turbulentas.

Para verificar a relação entre o fluxo de $\mathrm{CO}_{2}$ e a radiação solar, utilizamos fator de nebulosidade (Crawford and Duchon ,1998):

onde $R s i$ é a radiação solar incidente medida e $R s i_{(c l r)}$ é obtida de um modelo de radiação solar incidente a céu claro. Para medição dos fluxos dos escalares pelo MCT, instalamos uma estação micrometeorológica em uma ilha no reservatório de Itaipu. A descrição do local de estudo e dos equipamentos da estação estão na seção seguinte.

\section{MATERIAIS E MÉTODOS}

Os fluxos de $\mathrm{CO}_{2}$ apresentados neste trabalho são de uma campanha de monitoramento que se iniciou no dia 08/12/2012 e terminou no dia 21/12/2012.

A estação micrometeorológica foi instalada em uma ilha do reservatório de Itaipu localizada nas proximidades da cidade de Missal do Estado do Paraná. As coordenadas geográficas da ilha são latitude $-25^{\circ} 03^{\prime} 25,72$ e longitude $-54^{\circ} 24^{\prime} 33,67$, e a altitude em relação ao mar é de $220 \mathrm{~m}$. Na Figura $1^{\text {a }}$, está mostrada a estação micrometeorológica e na Figura 1d vê-se o ângulo do vento em relação ao norte magnético cujos dados estamos descartando por haver alguma vegetação na ilha atrás da torre micrometeorológica em relação à direção predominante do vento.

$\mathrm{Na}$ estação micrometeorológica, instalamos sensores que podem ser divididos em dois grupos: um grupo denominado por conjunto rápido, que são os sensores que medem as flutuações das concentrações turbulentas, e outro grupo denominado por conjunto lento, pois são os sensores que medem com frequência incapaz de detectar as flutuações turbulentas.

No conjunto rápido, as medições foram realizadas a $20 \mathrm{~Hz}$ e os sensores instalados foram: um anemômetro sônico CSAT3 (Campbell Scientific) instalado a 3,76 m acima do solo e configurado para medir as três componentes da velocidade do vento $\left(\mathrm{m} \mathrm{s}^{-1}\right)$ e a temperatura sônica $\left({ }^{\circ} \mathrm{C}\right.$ ); um analisador de gases LI7500 (Licor) instalado na mesma altura do CSAT3 e configurado para medir concentração de dióxido de carbono $\left(\mathrm{mmol} \mathrm{m}^{-3}\right)$, concentração de vapor de água $\left(\mathrm{mmol} \mathrm{m}^{-3}\right)$ e pressão (hPa); e quatro termopares FW03 (Campbell Scientific) configurados para medir temperatura do ar $(\mathrm{mV})$. A disposição dos sensores pode ser vista na Figura $1 b$. 
No conjunto lento, as medições foram realizadas a $0,1 \mathrm{~Hz}$ e os sensores utilizados foram: quatro sondas de dióxido de carbono GMP343 (Vaisala) configuradas para medir concentração de dióxido de carbono ( $\mathrm{ppm}$ ), uma sonda de temperatura e umidade relativa CS500 (Campbell Scientific) configurada para medir temperatura do ar $\left({ }^{\circ} \mathrm{C}\right)$ e umidade $(\%)$, um barômetro 61302V (Young) configurado para medir pressão $(\mathrm{hPa})$, um piranômetro SP LITE (Kipp \& Zonen) configurado para medir radiação $\left(\mathrm{Wm}^{-2}\right)$ e um pluviômetro (MRI) configurado para medir chuva $(\mathrm{mm})$.

Para medir a temperatura da água, instalaram-se dois sensores L108 da Campbell Scientific em uma bóia náutica, como pode se observar na Figura 1c.
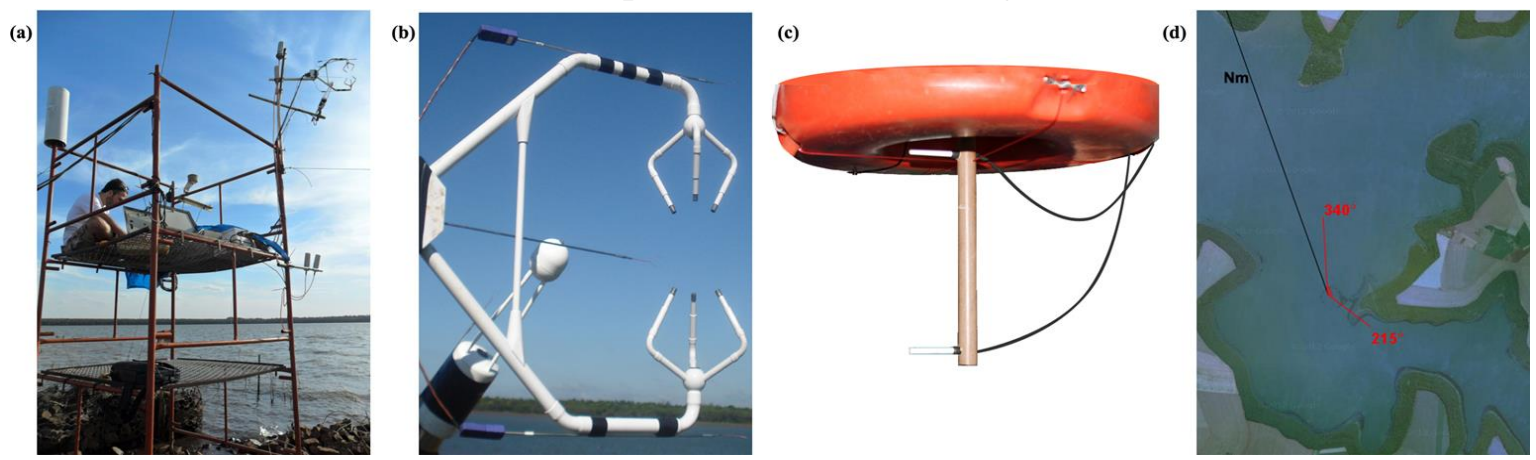

Figura 1: (a) Estação micrometeorológica instalada em ilha do reservatório de Itaipu, (b) sensores de resposta rápida, (c) boia náutica com sensores de temperatura, (d) ângulo do vento cujos dados foram descartados por haver vegetação na ilha

\section{RESULTADOS}

$\mathrm{Na}$ figura 2 apresentamos os fluxos de dióxido de carbono observados e a correspondente radiação solar incidente.
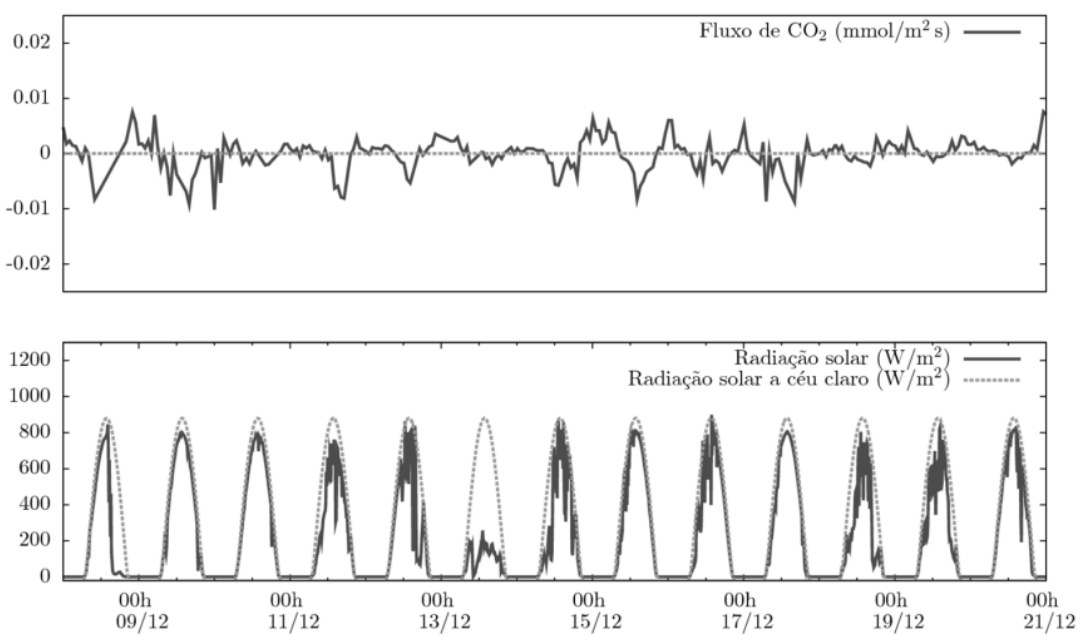

Figura 2: Fluxo de $\mathrm{CO}_{2}$ e radiação solar medidos na campanha de dezembro de 2012

Nota-se na Figura 2 que há assimilação de $\mathrm{CO}_{2}$ nos períodos diurnos. Para verificar se há correlação entre a intensidade da radiação solar e o fluxo de $\mathrm{CO}_{2}$ no período diurno, apresenta-se o diagrama da Figura 3, em que o fator de nebulosidade é plotado contra o fluxo de $\mathrm{CO}_{2}$ para os horários em que há radiação solar. 


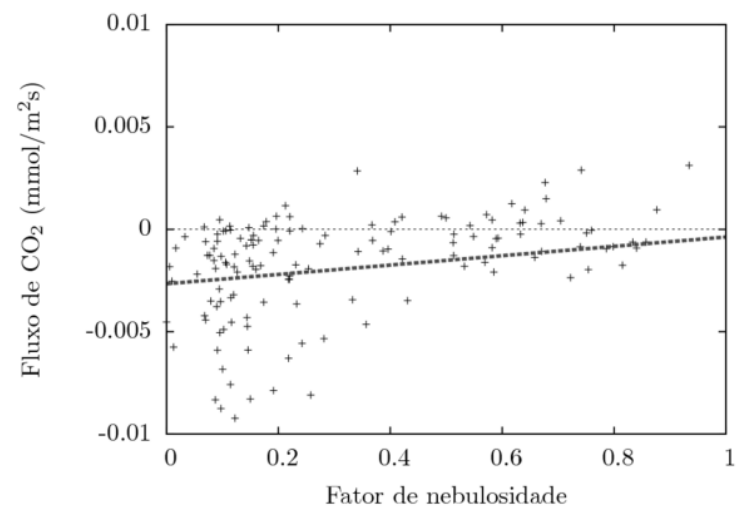

Figura 3: Fator de nebulosidade contra o fluxo de dióxido de carbono

Quanto mais próximo de zero é o fator de nebulosidade, mais radiação incide sobre o reservatório. Assim, observa-se na Figura 3 que a fixação do $\mathrm{CO}_{2}$ é maior para condições de menor nebulosidade.

$\mathrm{Na}$ figura 4 investiga-se se há correlação entre a temperatura da água e do ar com o fluxo de $\mathrm{CO}_{2}$.
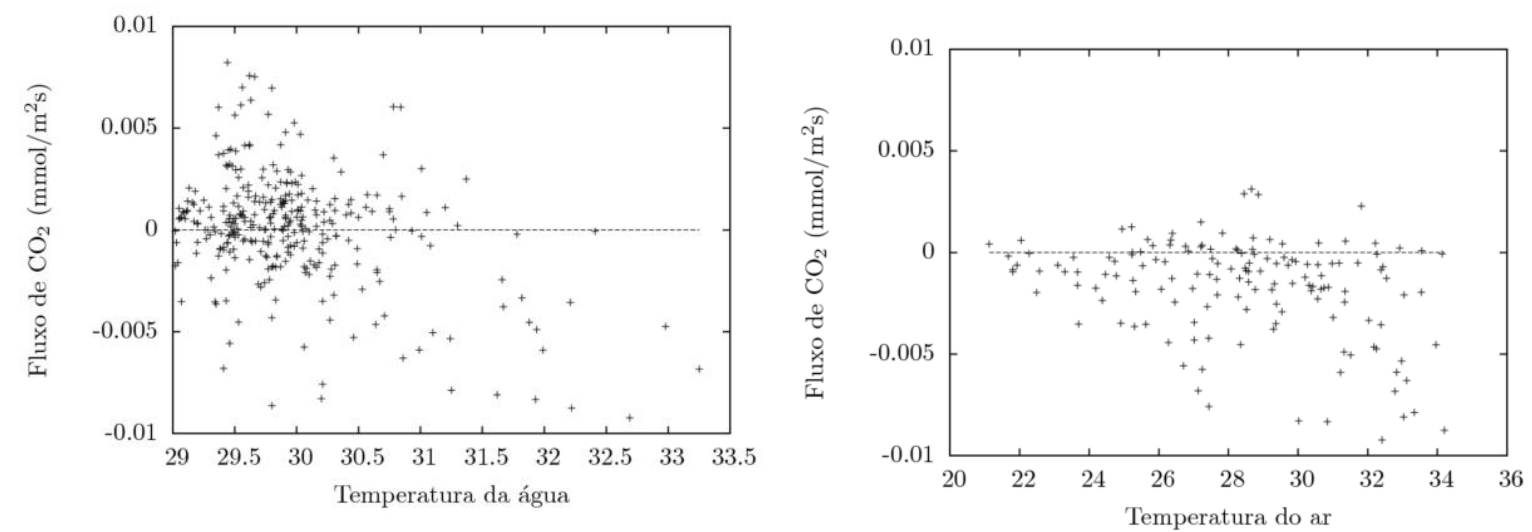

Figura 4: (a) Temperatura da água contra o fluxo de dióxido de carbono, (b) temperatura do ar contra o fluxo de dióxido de carbono

Nota-se na Figura 4 que não há correlação bem definida entre a temperatura da água e a temperatura do ar com o fluxo de $\mathrm{CO}_{2}$. Zhu et al. (2010) obtiveram resultados semelhantes em dois lagos da Antárctica, com fluxos médios de $\mathrm{CO}_{2}$ negativos cuja intensidade era controlada pela radiação solar, sendo que a temperatura da água e do ar tinham baixa correlação com este fluxo.

\section{CONCLUSÃO}

Uma estação micrometeorológica foi instalada sobre uma ilha do reservatório da usina hidrelétrica de Itaipu. Constatou-se nos fluxos turbulentos de $\mathrm{CO}_{2}$ medidos em uma campanha de 13 dias em dezembro de 2012 que há assimilação de $\mathrm{CO}_{2}$ no reservatório. Investigou-se a correlação entre o fluxo de $\mathrm{CO}_{2}$ e as variáveis temperatura do ar, temperatura da água e radiação solar incidente, e observou-se que a intensidade da radiação solar controlava a magnitude do fluxo de $\mathrm{CO}_{2}$ na região monitorada do reservatório de Itaipu. 


\section{RECONHECIMENTOS}

Este trabalho foi realizado com recursos do projeto FUNPAR 2882 financiado pela Companhia Hidro Elétrica do São Francisco (CHESF), da Chamada ANEEL 009/2008, Projeto Estratégico "Monitoramento das Emissões de Gases de Efeito Estufa em Reservatórios de Usinas Hidrelétricas", do Fundo Setorial de Energia Elétrica.

\section{BIBLIOGRAFIA}

Crawford, M. T., Duchon e C. E. (1998). An Improved Parameterization for Estimating Effective Atmospheric Emissivity for Use in Calculating Daytime Downwelling Longwave Radiation. Journal of Applied Meteorology, (38): 474-480

Rudd, J. W. M., Harris, R, Kelly, C. A. e Hecky, R. E. (1994). Are Hydroelectric Reservoirs Significant Sources of Greenhouse Gases? Ambio, 22 (4): 246-248

Paw U, K. T., Baldocchi, D. D., Meyers, T. P. e Wilson, K. B. (2000). Correction of eddycovariance measurements incorporating both advective effects and density fluxes. Boundary-Layer Meteorology, (97):487-511

Zhu, R., Liu, Y., Xu, H., Huang, T., Sun, J., Ma, E., Sun, L. (2010). Carbon dioxide and methane fluxes in the littoral zones of two lakes, east Antarctica. Atmospheric Environment, (44): 304-311 